\title{
Performance enhancement of asphalt patch repair with innovative heating strategy
}

1 Juliana Byzyka BSC (Hons), MSC, PhD, AFHEA, GMICE, MIET Lecturer in Civil Engineering, School of Computing, Science and Engineering, University of Salford, Manchester, UK (corresponding author: j.byzyka@salford.ac.uk)

2 Mujib Rahman BS, MSc, PhD, CEng, FCIHT, MICE, FHEA Senior Lecturer in Civil Engineering, Department of Mechanical, Aerospace and Civil Engineering, Brunel University, London, UK
3 Denis Albert Chamberlain BSc, DIC, MSc, PhD, MCS, FICE Professor in Civil Engineering, Department of Mechanical, Aerospace and Civil Engineering, Brunel University, London, UK

4 Marina Malieva MSc, MBA

International Sales Manager, Cooper Technology, Ripley, UK
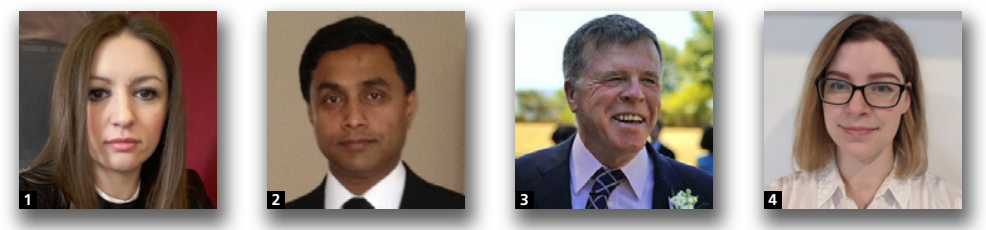

The advantage of controlled preheating of an excavated asphalt surface prior to hot-mix asphalt patch repair, referred to as 'dynamic repair', is presented in this paper. The heating effects are compared with traditional repair, referred to as 'static repair'. Shear bond and immersion wheel tracking tests were performed to assess the quality of both types of repair. Pothole excavations were created in the laboratory environment. For the static repairs, a tack coat was applied at the interfaces of the excavation prior to laying the hot repair material. For the dynamic repairs, infrared heat was applied in heating-cooling cycles prior to filling the excavation with hot-mix material, without the use of a tack coat. Heat was applied using an experimental infrared heater set at $6.6 \mathrm{~kW}$ with a $230 \mathrm{~mm}$ offset from the excavation. The results showed that the shear strength at the bottom and vertical interfaces of the dynamic repairs was, respectively, $\mathbf{7 8 . 2} \%$ and $\mathbf{6 8 . 4 \%}$ higher than that of the static repairs. The immersion wheel tracking test showed that the resistance to water-related damage of the dynamic repairs was higher than that of the static repairs. It is concluded that preheating a pothole excavation with infrared heat prior to filling and compaction increases the repair interface bonding strength and durability.

\author{
Notation \\ D specimen diameter $(\mathrm{m})$ \\ d diameter $(\mathrm{mm})$ \\ $h \quad$ height (mm) \\ $P_{\max } \quad$ maximum load applied to specimen $(\mathrm{kg})$ \\ $\tau_{\max } \quad$ maximum shear stress $\left(\mathrm{kg} / \mathrm{m}^{2}\right)$
}

\section{Introduction}

Asphalt consists of aggregate, bitumen and air voids, with aggregate comprising $94-95 \%$ of the mass of hot-mix asphalt (Prowell et al., 2005). Although asphalt pavements can expand and contract under temperature variations and movement, they still deteriorate. The main causes of pavement distresses are repeated traffic loading, environmental conditions, bitumen ageing, a weak subgrade and poor pavement structure (Chatti et al., 2004; Lesueur and Youtcheff, 2013; Mfinanga et al., 1996; Walker, 1984). Typical failures are cracking, rutting, ravelling and potholing (Adlinge and Gupta, 2013). Potholes are well known for causing traffic disruptions and accidents to road users.

In addition to traffic- and temperature-related damage, exposure to water causes aggregate dislodging, stripping and ravelling. Ravelling results from water infiltration into the pavement, which weakens the mastic cohesion and mastic adhesion bond to the coarse aggregate particles. Repeated traffic loading and water action leads to initial stripping, severe ravelling and then to potholing (Dawson, 2008). Therefore, many potholes usually appear after wet weather conditions and are dramatically increased after freezing and thawing cycles (Lavin, 2003).

Common pothole repair practices are pothole filling and patching. Pothole filling is considered to be a temporary repair method, which is further divided into 'throw and go', 'throw and roll', semi-permanent and injection. Patching is a permanent repair and, except for potholes, is used to treat other asphalt pavement distresses such as alligator cracking, pavement depressions, rutting, corrugations and slippage cracks. Typically, pothole filling is performed as an emergency repair, mainly during winter time, until a permanent repair is provided. Dense-graded hot-mix asphalt is commonly used for patching. Typical nominal aggregate sizes for small patches are $12.5 \mathrm{~mm}$ and $9.5 \mathrm{~mm}$ (Lavin, 2003). However, the depth of the pothole should be considered when choosing the aggregate size (McDaniel et al., 2014). 
Failures in asphalt patching can occur due to the material used, the repair process or nearby pavement deterioration (McDaniel et al., 2014). Common failures are bleeding or flushing, dishing, debonding, ravelling, pushing and shoving (Prowell and Franklin, 1996). Debonding - the lack of fill mixture adhesion with the old pavement (McDaniel et al., 2014) - was the repair failure studied in this research. One method currently used to avoid debonding is infrared patching. When a pothole is repaired using this method, an infrared heater is placed above the distressed area at a chosen offset, to soften the asphalt. At the end of the heating, the heater is removed and the heated area is scarified. Then, rejuvenator is added to the old mixture to reinstate its properties, new hotmixture is poured to fill the hole fully and finally compacted.

The use of infrared heating in asphalt patching aims to improve interface bonding and repair durability, decrease repetitions of the same patching and reduce the costs of labour, equipment, traffic control and long disruption times (Nazzal et al., 2014). Both infrared and microwave technology have been used in patching operations and repair of asphalt cracks for more than 30 years, although they have not been reported under controlled conditions (Clyne et al., 2010; Freeman and Epps, 2012; Leininger, 2015; McDaniel et al., 2012; Nazzal et al., 2014; Uzarowski et al., 2011). Furthermore, the effect of the thermal properties of asphalt mixtures in the heating process and the influence of other parameters such as pothole geometry, environmental conditions and temperatures achieved within the repair build have not been considered.

Against this background, the objective of the work reported in this paper was to compare the performance of dynamically heated pothole repairs against static repairs. To this end, shear bond tests and wheel tracking tests were performed. In this paper, a dynamic repair means intermittent infrared-heated pothole excavation prior to its repair, while a static repair is a non-heated traditional pothole repair. Dynamic heating regimes for shallow and deep potholes using infrared heat have previously been investigated by the authors (Byzyka et al., 2018a). These were adopted for the dynamic repairs in this work, with heating times of $10 \mathrm{~min} 15 \mathrm{~s}$ and $21 \mathrm{~min} 49 \mathrm{~s}$.

\section{Materials and experimental methods}

\section{$2.1 \quad$ Experimental programme}

In total, 18 slabs were fabricated to investigate the repair interface bonding and rutting performance of static and dynamic repairs. Two pothole excavations were repaired per slab for simultaneous testing of the repair methods. For shear bond tests, two dynamic heating times ( $10 \mathrm{~min} 15 \mathrm{~s}$ and $21 \mathrm{~min} 49 \mathrm{~s}$ ) were used to make the dynamic repairs. For the wheel tracking tests, dynamic repairs with $10 \mathrm{~min} 15 \mathrm{~s}$ preheating times were tested. These heating durations were derived from previous work by the authors (Byzyka et al., 2018a). The experimental programme and test parameters are summarised in Table 1.

\subsection{Materials}

The selection of the constituent materials of an asphalt mixture for the construction of a pavement in a particular area depends mostly on traffic, climate and layer thickness. For pavement structures designed to facilitate high traffic loading, a 40/60 penetration grade bitumen binder is suitable for both base and binder courses, whereas the use of a harder bitumen such as 30/45 penetration grade bitumen binder is suitable for surface courses. In the case of a pavement structure designed for lower traffic loading, a softer bitumen type can be used for all courses. Therefore, for base and binder courses the binder can be 70/100 penetration grade bitumen and for surface courses it can be either $70 / 100$ or $100 / 150$ penetration grade bitumen. Furthermore, for very highly trafficked roads, modified bitumens may also be considered for the surface course. The choice of aggregates for all pavement courses depends on the demand in traffic for the specific area for which the pavement is being designed and the in-place conditions where the pavement is going to be constructed (BSI, 2005). Therefore, since the choice of bitumen and aggregates depends on the factors explained above and the number of asphalt mixtures resulting from the above is considerable, one type of dense asphalt mixture was used in this research.

The slabs were made with dense gradation $(20 \mathrm{~mm}$ dense bitumen macadam (DBM)) comprising coarse and fine granite aggregate and limestone filler. The bitumen used was 100/150 penetration grade. The pothole excavations were repaired with a $6 \mathrm{~mm}$ dense graded mixture (AC-6). Figure 1 shows the composition of the asphalt mixtures. The mix design conformed to BS EN 13108-1 (BSI, 2016a) and the bitumen grade conformed to the specifications of Highways England et al. (2008). The aggregate, filler and bitumen were heated to $110 \pm 5^{\circ} \mathrm{C}$ and $140 \pm 5^{\circ} \mathrm{C}$, respectively, prior to mixing and then mixed at $140 \pm 5^{\circ} \mathrm{C}$ in a laboratory mixer for approximately 4 min (BSI, 2016b).

\subsection{Description of dynamic heating}

Previously reported work on the optimum dynamic heating methods for a $45 \mathrm{~mm}$ deep pothole excavation was consulted. Dynamic heating was performed with an experimental infrared heater, as reported by Byzyka et al. (2019). Heat was applied in heating-cooling cycles to avoid severe ageing or charring of the surface asphalt binder (Huang et al., 2016) and preheating was applied to both the pothole excavation faces and the inside of the host asphalt pavement. For the heating part of the cycle, the heater was set at a heating power of $6.6 \mathrm{~kW}$. The thermal effect of preheating repair interfaces has been previously investigated by the authors (Byzyka et al., 2018b).

\subsection{Construction of slabs and repairs}

Asphalt slabs of dimensions $695 \times 695 \times 100 \mathrm{~mm}^{3}$ were constructed in two lifts of approximately $50 \mathrm{~mm}$ depth. Each lift 

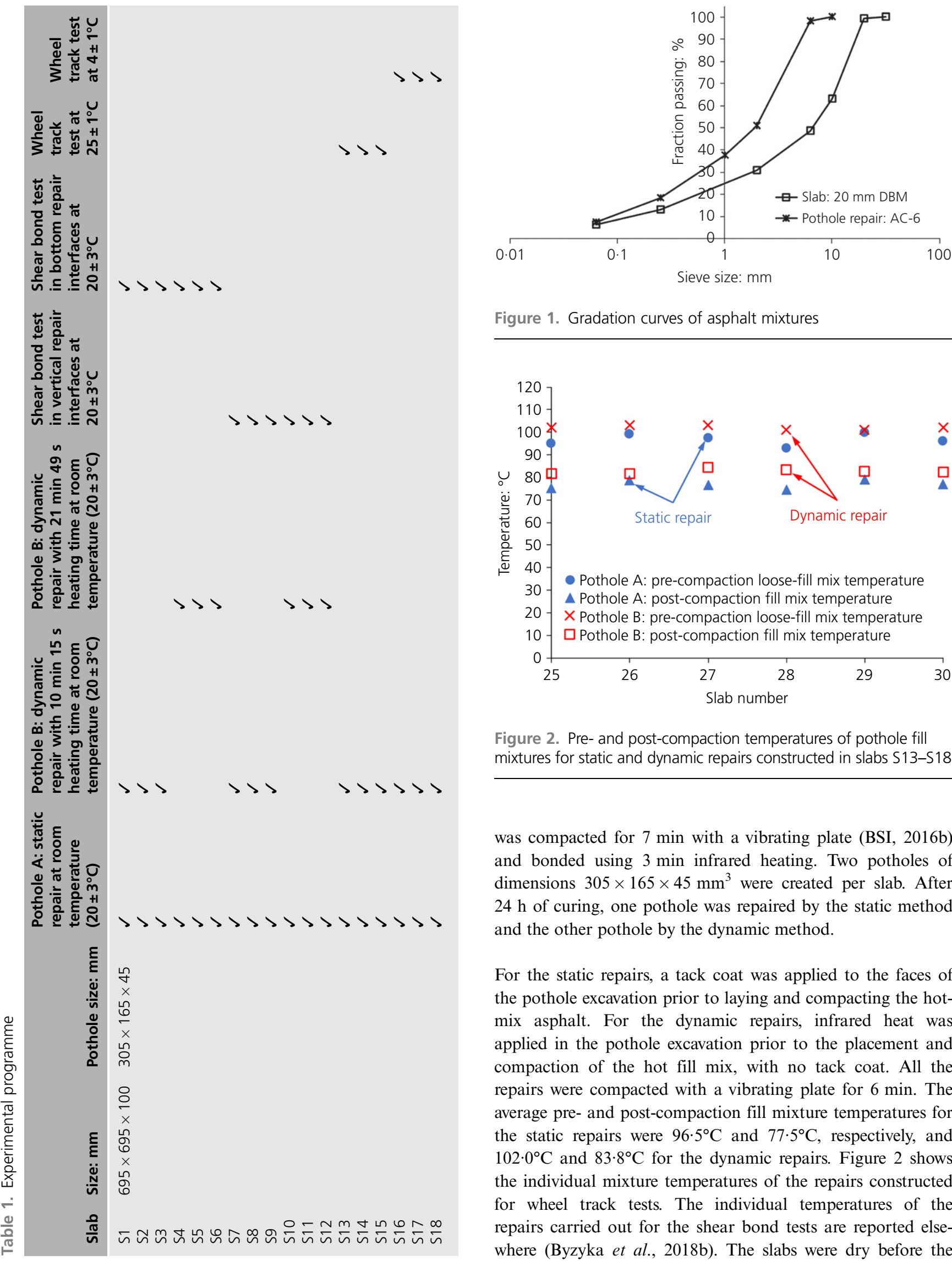

Figure 1. Gradation curves of asphalt mixtures

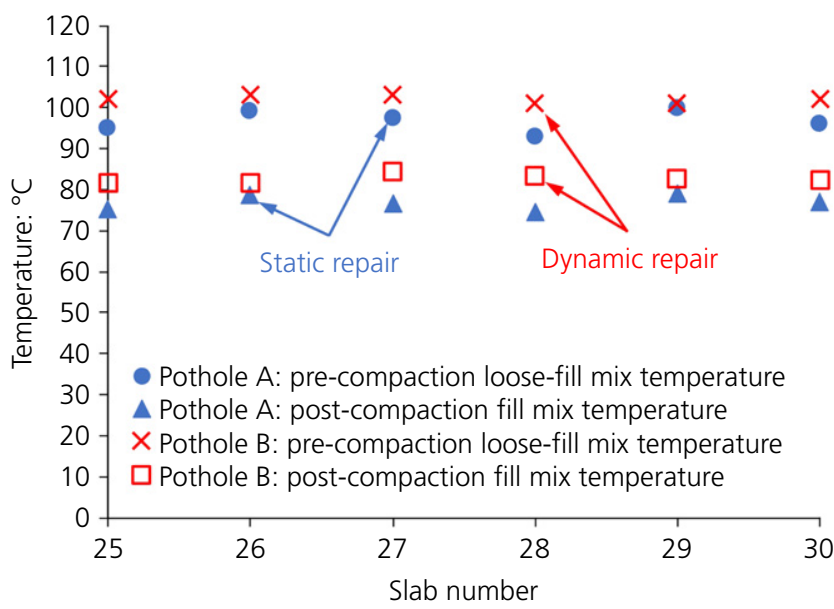

Figure 2. Pre- and post-compaction temperatures of pothole fill mixtures for static and dynamic repairs constructed in slabs S13-S18

was compacted for $7 \mathrm{~min}$ with a vibrating plate (BSI, 2016b) and bonded using $3 \mathrm{~min}$ infrared heating. Two potholes of dimensions $305 \times 165 \times 45 \mathrm{~mm}^{3}$ were created per slab. After $24 \mathrm{~h}$ of curing, one pothole was repaired by the static method and the other pothole by the dynamic method.

For the static repairs, a tack coat was applied to the faces of the pothole excavation prior to laying and compacting the hotmix asphalt. For the dynamic repairs, infrared heat was applied in the pothole excavation prior to the placement and compaction of the hot fill mix, with no tack coat. All the repairs were compacted with a vibrating plate for $6 \mathrm{~min}$. The average pre- and post-compaction fill mixture temperatures for the static repairs were $96.5^{\circ} \mathrm{C}$ and $77.5^{\circ} \mathrm{C}$, respectively, and $102.0^{\circ} \mathrm{C}$ and $83.8^{\circ} \mathrm{C}$ for the dynamic repairs. Figure 2 shows the individual mixture temperatures of the repairs constructed for wheel track tests. The individual temperatures of the repairs carried out for the shear bond tests are reported elsewhere (Byzyka et al., 2018b). The slabs were dry before the 
Performance enhancement of asphalt patch repair with innovative heating strategy

Byzyka, Rahman, Chamberlain and Malieva

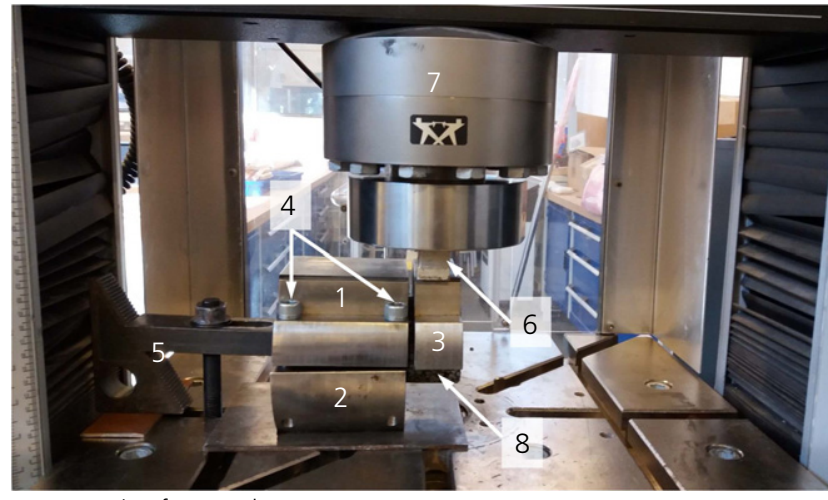

1 Upper ring for sample support 2 Lower ring for sample support

3 Shear ring

4 Four bolts for holding upper and lower rings

5 Support for lower ring to keep it stable

6 Aluminium block to separate load head from shear ring

7 Load from Instron hydraulic machine

8 Asphalt sample test

Figure 3. Shear bond test apparatus designed for this study

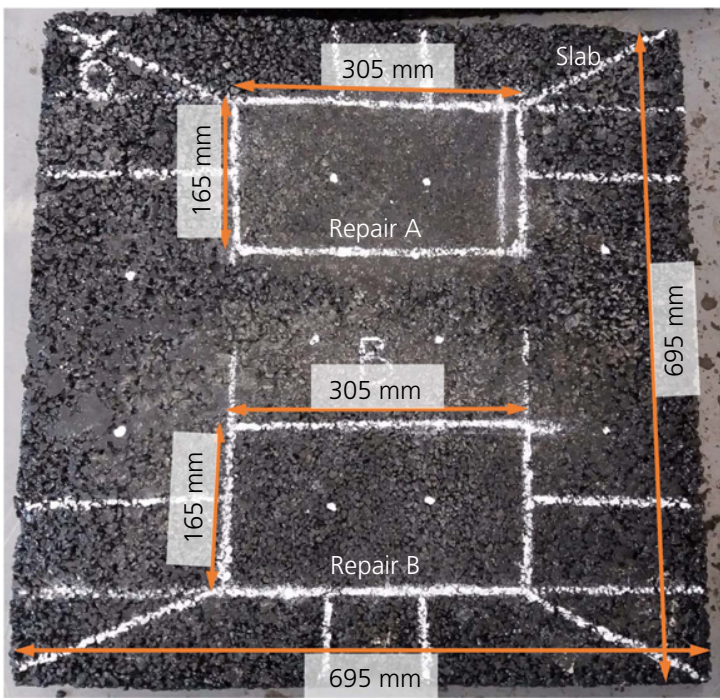

(a) repairs were carried out, and the slabs and repairs were constructed at room temperature, $20 \pm 3^{\circ} \mathrm{C}$.

\subsection{Air void contents of slabs and repairs}

Air void contents in the range $12 \cdot 43-13 \cdot 28 \%$ were determined for slabs S1-S12 and the repairs in slabs S1-S6 using a previously reported method (Aashto, 2005, 2007; Roberts et al., 1991). The air voids content for the static and dynamic repairs was around $4.5 \%$ and $4 \cdot 7 \%$, respectively. Air void contents were not measured for all the slabs and repairs because they were cut to perform different tests. However, a similar level of air voids was expected to have been achieved for all samples due to the consistency of slab construction and repair formation.

\subsection{Shear bond tests}

Shear bond tests were used to evaluate the bonding at the interfaces of both the static and dynamic repairs in slabs S1-S12. These tests were conducted using an Instron hydraulic machine together with a shearing rig specifically designed for

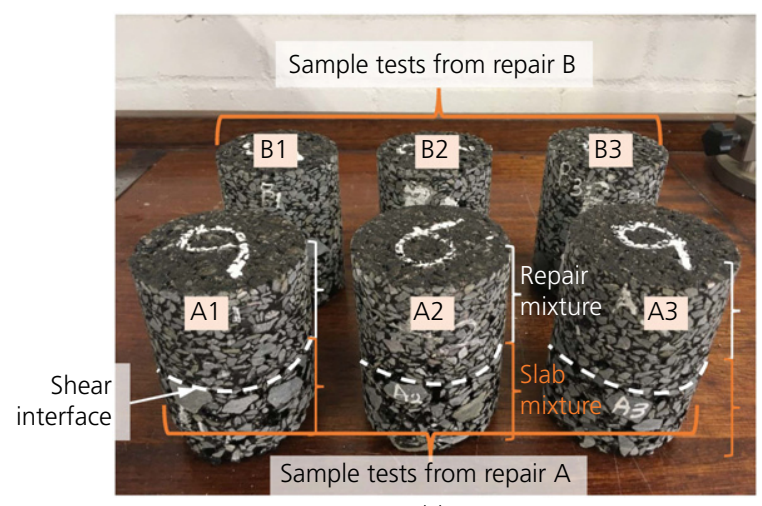

(c)

Figure 4. Sample tests for shear bond tests of bottom repair interfaces (slabs S1-S6; see Table 1): (a) asphalt slab; (b) coring; (c) test cores 
Transport

Volume 175 Issue 5
Performance enhancement of asphalt patch repair with innovative

heating strategy

Byzyka, Rahman, Chamberlain and Malieva this study (Figure 3). The shearing rig was designed in accordance with the work of Raposeiras et al. (2013) for a $70 \mathrm{~mm}$ dia. extracted core. Shear bond testing was conducted as per the work of Obaidi et al. (2017).
To determine the bonding at the bottom interface of the repairs, test samples were cored for each repair, as shown in Figure 4. For the vertical repair interfaces, the slabs were first cut into smaller blocks using a wet saw and then cored. The

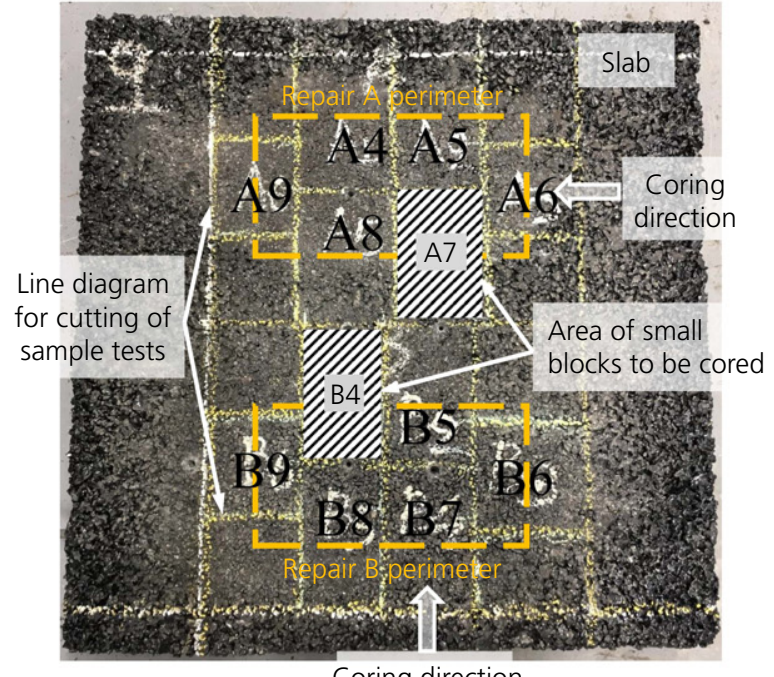

Coring direction

(a)

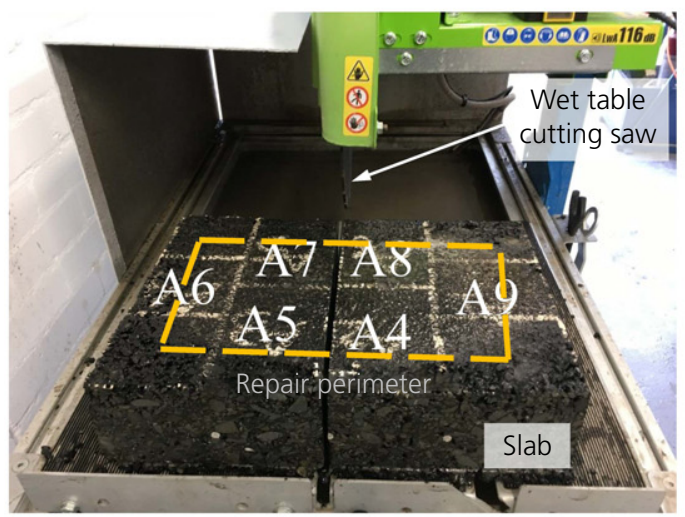

(c)

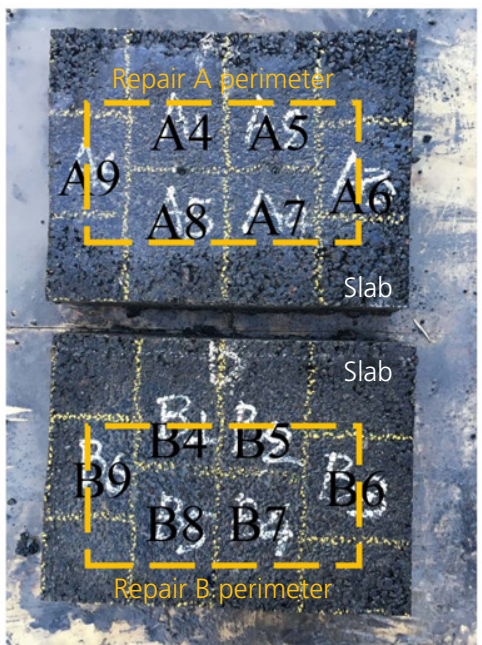

(b)

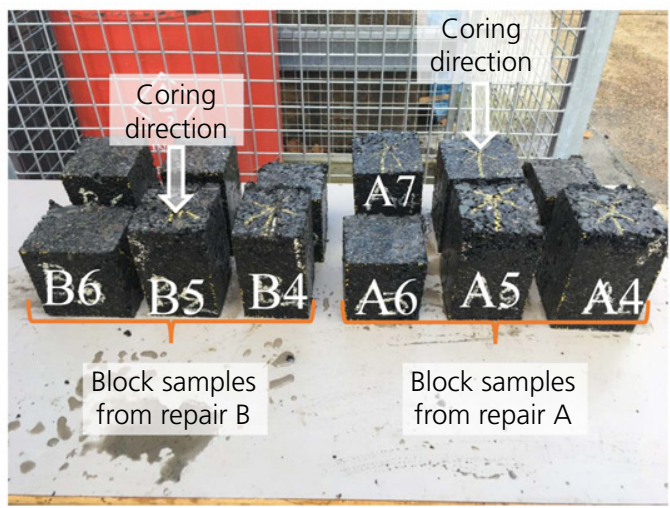

(d)

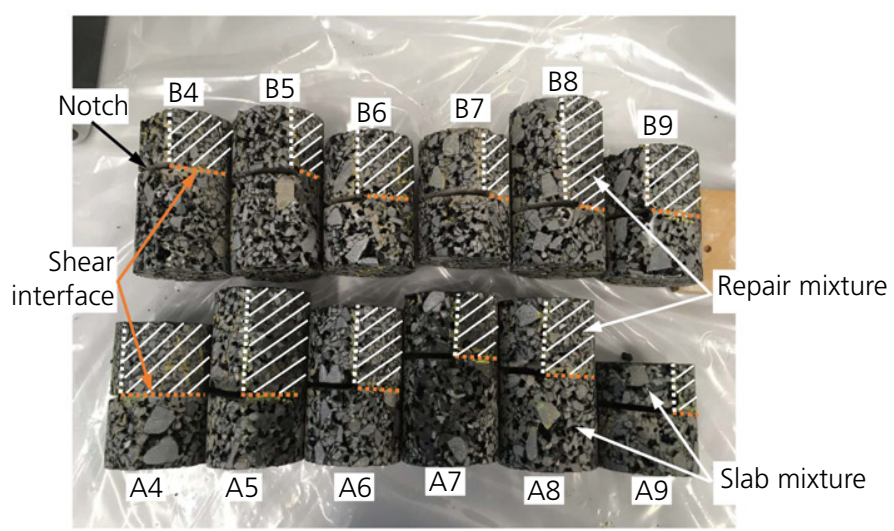

(e)

Figure 5. Samples for shear bond tests of vertical repair interfaces (slabs S7-S12; see Table 1): (a) step 1, marking of slab; (b) step 2, cutting of slab; (c) step 3, cutting of slab blocks; (d) step 4, coring of asphalt blocks; (e) step 5, final samples 
Transport

Volume 175 Issue 5
Performance enhancement of

asphalt patch repair with innovative

heating strategy

Byzyka, Rahman, Chamberlain and Malieva coring direction was perpendicular to the repair interface. A notch was created in the cores to concentrate loading on the repair interface (Figure 5).

After curing the test cores at room temperature $\left(20 \pm 3^{\circ} \mathrm{C}\right)$ for $24 \mathrm{~h}$, they were sheared to failure. The shear displacement rate was $20 \mathrm{~mm} / \mathrm{min}$. The gap between the shearing platens was $5 \mathrm{~mm}$ and the tests were also conducted at room temperature $\left(20 \pm 3^{\circ} \mathrm{C}\right)$. The maximum shear stress was calculated using Equation $1(\mathrm{Du}, 2015)$

1. $\tau_{\max }=\frac{4 P_{\max }}{\pi D^{2}}$ where $\tau_{\max }$ is the maximum shear stress $\left(\mathrm{kg} / \mathrm{m}^{2}\right), P_{\max }$ is the maximum load applied to specimen $(\mathrm{kg})$ and $D$ is the specimen diameter (m).

\subsection{Wheel tracking tests}

Figure 6 shows the preparation of test samples for the wheel tracking tests. The tests carried out at $25 \pm 1^{\circ} \mathrm{C}$ were conducted using a Hamburg wheel tracking device in accordance with Aashto T 324 (Aashto, 2004) with a test tank and moulds specifically designed for this study. The tests performed at $4 \pm 1{ }^{\circ} \mathrm{C}$ were non-standard but, nevertheless, a similar procedure was followed. The $4 \pm 1^{\circ} \mathrm{C}$ temperature was controlled with a $\mathrm{K} 1$ chiller integrated with the wheel tracking device. The static and dynamic repairs were tested simultaneously.

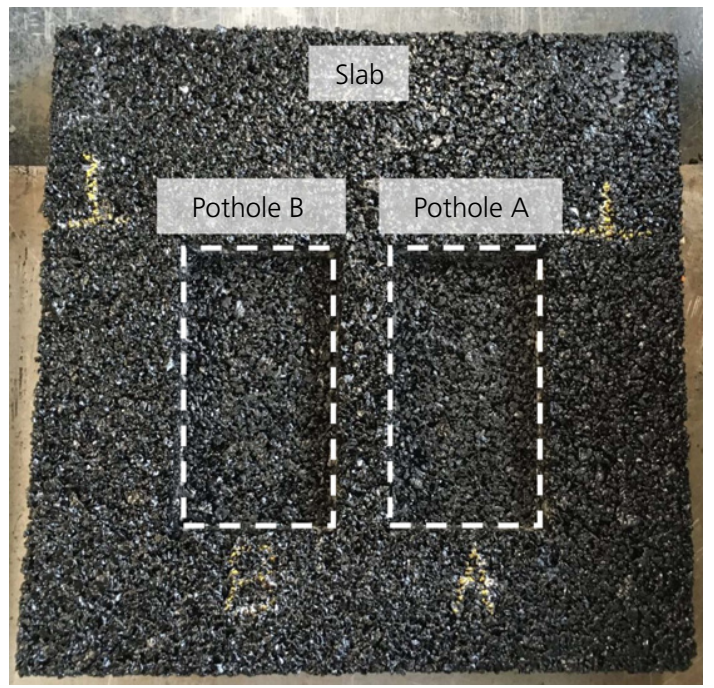

(a)

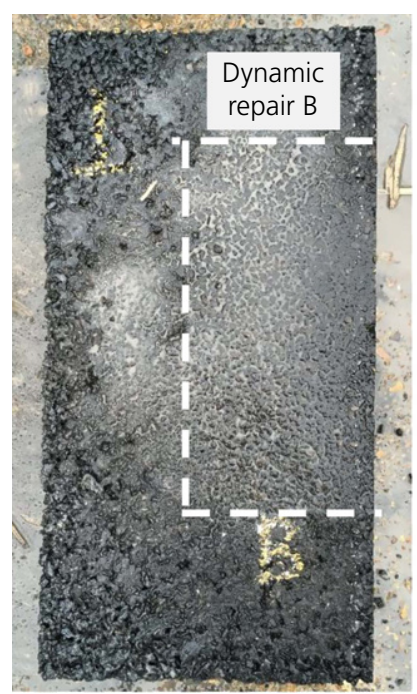

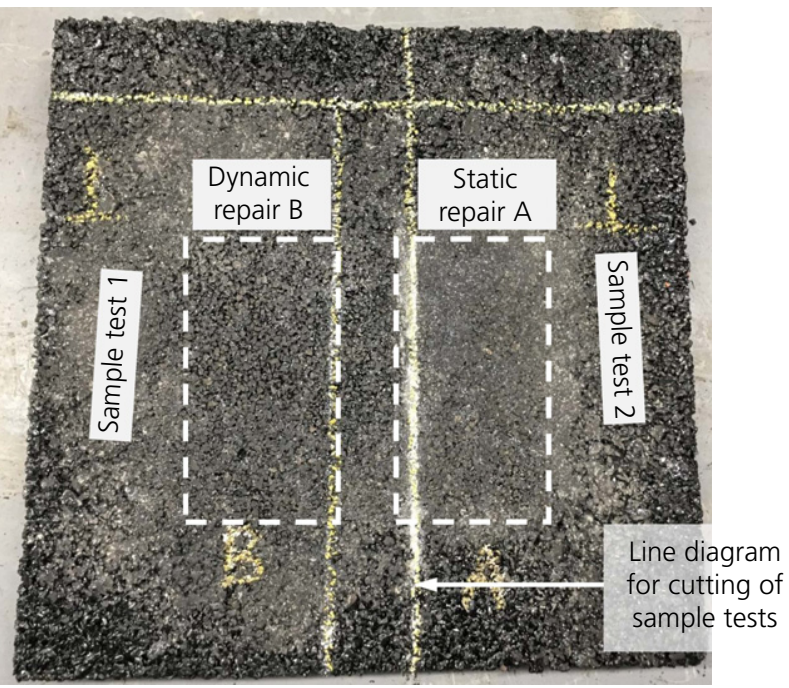

(b)

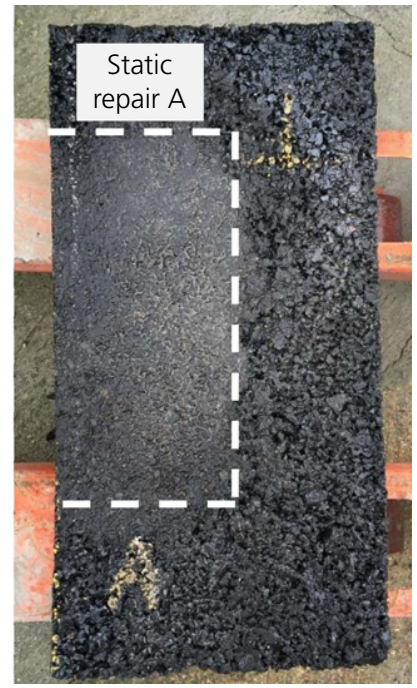

(c)

Figure 6. Samples for wheel tracking test: (a) host pavement; (b) repaired potholes in host pavement; (c) sample blocks 
Transport

Volume 175 Issue 5
Performance enhancement of

asphalt patch repair with innovative

heating strategy

Byzyka, Rahman, Chamberlain and Malieva
20000 cycles were applied to each repair, as shown in Figure 7. The rutting depth was measured at $4 \mathrm{~mm}$ spacings along $96 \mathrm{~mm}$ of the repair interface. The tests were conducted $24 \mathrm{~h}$ after completion of the repairs.
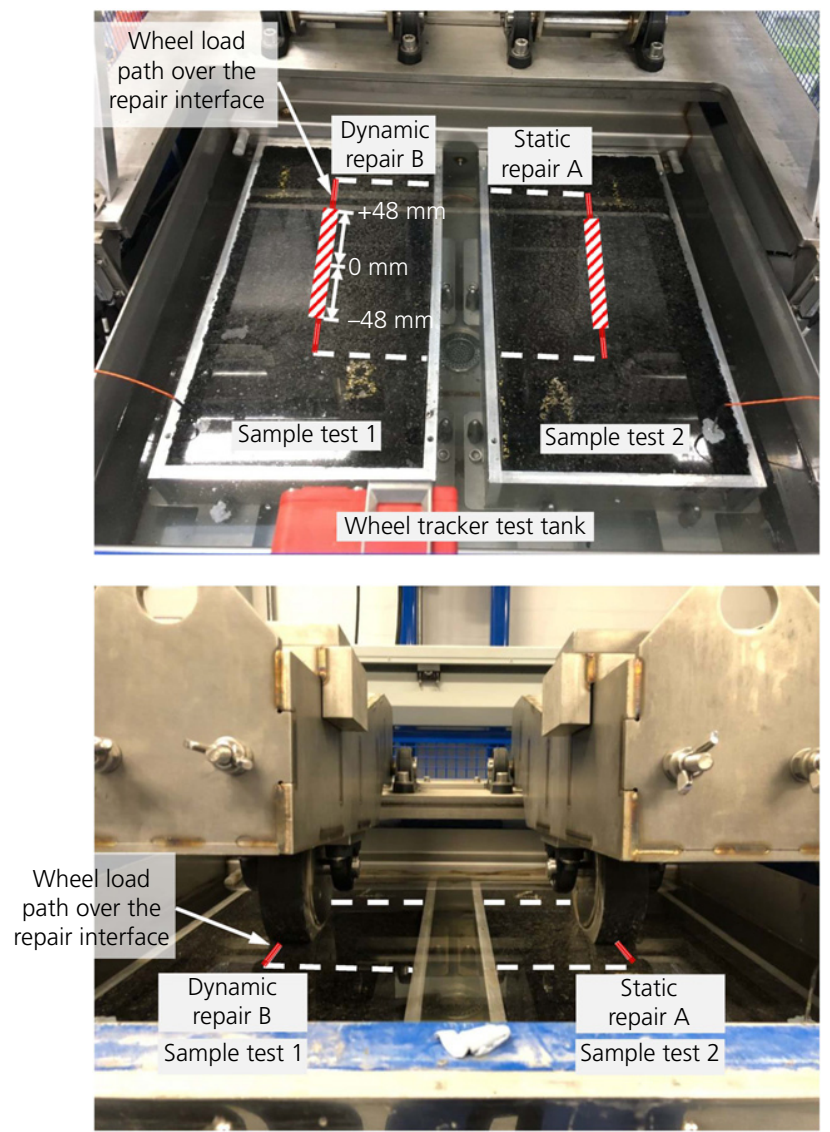

Figure 7. Simulation of wheel loads in the interface of static and dynamic repairs

\section{Results, analysis and interpretation}

\subsection{Interface shear strength testing}

Figure 8 shows the average interface shear strengths for the static (samples A) and dynamic (samples B) repair methods with heating durations of $10 \mathrm{~min} 15 \mathrm{~s}$ and $21 \mathrm{~min} 49 \mathrm{~s}$. To investigate the interface shear strength at the bottom repair interface of the static repairs, 18 test cores were used. Sets of nine cores were tested for both heating durations of the dynamic repairs. 36 cores were used to investigate the shear strength of the vertical repair interface of the static repairs and 18 cores per heating time were used for similar tests of the dynamic repairs. All the tests produced failure of the bonding interface. Four cores taken from the vertical interface of static repairs failed as soon as they were put on the shearing rig. These failures are included in Figure 8. Four further tests were aborted due to equipment failure.

The first observation from the results was that the interface shear strengths with the dynamic repair method were significantly higher those for the static method repairs. The shear strengths at the bottom repair interfaces of the dynamic repairs were consistent, with values of about $0.499 \mathrm{MPa}$ and $0.579 \mathrm{MPa}$; these values were, on average $78.2 \%$ higher than the shear strengths of the static repairs. This is because, for the dynamic repairs, there was a reduction in bitumen viscosity with continuing heating. Lower viscosity means less resistance of the asphalt to flow, higher interlocking between the aggregates of the host pavement and the fill mixture, and adequate adhesion between the repair interfaces. This also justifies the finding that a slightly higher bond strength was obtained for test samples A2 and B2, which were cored in the middle of the repairs where the temperatures during preheating and repair were the highest. Between the heating durations of $10 \min 15 \mathrm{~s}$ and $21 \mathrm{~min} 49 \mathrm{~s}$, there was no significant additional influence of heating on the shear bond strength of the bottom interface,

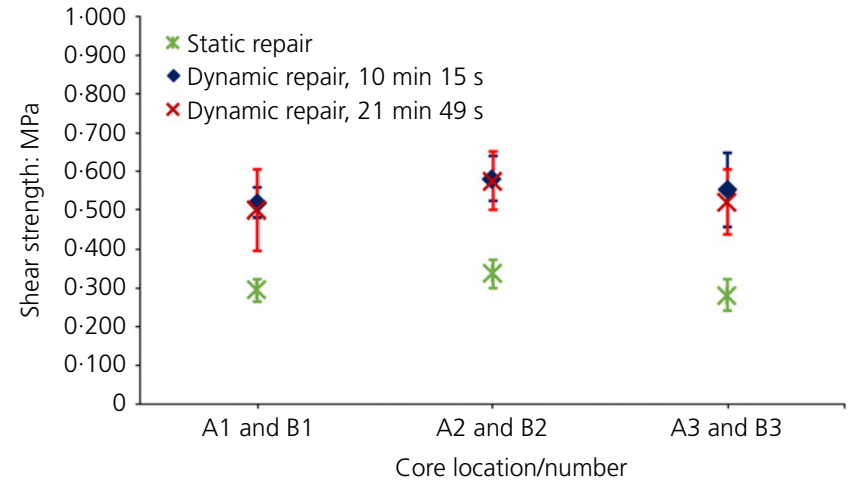

(a)

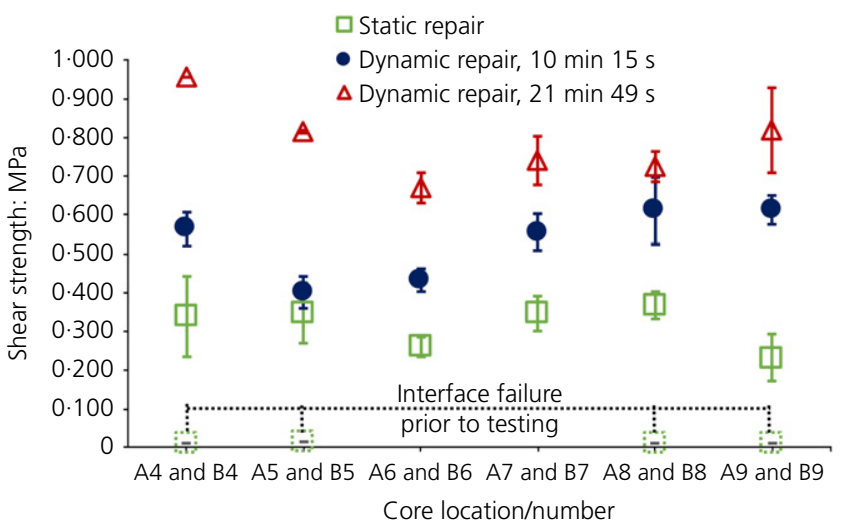

(b)

Figure 8. Interface shear strength for static and dynamic pothole repairs: (a) shear strength of bottom repair interface; (b) shear strength of vertical repair interfaces. Sample characterisation (A1-A9 and B1-B9) is given in Figures 3 and 4 . The error bars show the standard deviation of each value 
despite the natural reduction in bitumen viscosity. This was because the bottom face of the excavation was confined by the whole asphalt mixture of the host pavement during heating and repair compaction.

However, the effect of the asphalt's low viscosity during heating was apparent at the vertical faces of the excavation. These faces were not supported during heating and were free to move as soon as the bitumen softened and compaction of the fill mixture started. Thus, the shear strength of test samples B4 and B5 heated for $21 \mathrm{~min} 49 \mathrm{~s}$ was $0.392 \mathrm{MPa}$ and $0.416 \mathrm{MPa}$, respectively, higher than that of the samples prepared with a dynamic heating time of $10 \mathrm{~min} 15 \mathrm{~s}$. For test samples B6-B9, an average strength difference of only $0 \cdot 185 \mathrm{MPa}$ was observed. The shear strength differed between the test cores of the vertical faces of the dynamic repairs because different temperatures were achieved in pothole preheating. A previous investigation by the authors into similar dynamically heated asphalt excavations (Byzyka et al., 2018a) showed that, at the end of preheating, at the mid-bottom of the excavation surface, temperatures were typically in the range $140-160^{\circ} \mathrm{C}$, with lower temperatures $\left(80-120^{\circ} \mathrm{C}\right)$ on the vertical faces.

Furthermore, the strength at the vertical repair interfaces of the dynamic repairs was higher than that of the static repairs. In general, the strength of the test samples extracted from the $10 \mathrm{~min} 15 \mathrm{~s}$ dynamic repairs was $68.4 \%$ higher than the strength of test samples from the static repairs. The strength of the $21 \mathrm{~min} 49 \mathrm{~s}$ dynamically heated repairs was more than double that of the static repairs.

Considering the shear strength results obtained for the vertical interfaces of the excavation, it seems that there was a higher influence of temperature on the strength of the interface. However, during the two heating durations of the pothole excavation, it was observed that the sides became increasingly loose after $21 \mathrm{~min}$ of heating, showing evidence of overheating of the asphalt and the heating of an area larger than expected. This was not obvious for the bottom interface since the slab was confined in its mould when heating was applied. Besides, $21 \mathrm{~min}$ of heating would be expected to increase the overall repair time, which is less desirable (Wilson and Romine, 2001). The interface strength of the dynamic pothole repairs at the end of $10 \mathrm{~min} 15 \mathrm{~s}$ of heating was even higher than that of repairs completed with induction heating (Obaidi et al., 2017).

\subsection{Immersion wheel tracking testing}

Figure 9 shows the permanent deformation of individual static and dynamic repairs at the repair vertical interface for tests carried out at $25 \pm 1^{\circ} \mathrm{C}$ and at $4 \pm 1^{\circ} \mathrm{C}$. Figure 10 shows the average rutting profiles of these repairs along the interface. Six slabs were prepared for the wheel tracking tests. Sets of three static and three dynamic repairs were tested at both test temperatures. During the tests it was observed that the profile of the tested surfaces was non-uniform. This was captured from the wheel tracking machine at the first four passes, with the asphalt surface profile levels fluctuating between $\pm 1.4 \mathrm{~mm}$ and $\pm 1.7 \mathrm{~mm}$ in all the tests. This fluctuation was correspondingly added or subtracted from the final rutting depth in the results presented. It can be observed that, for the rutting test at $25^{\circ} \mathrm{C}$, the dynamic repairs outperformed the static repairs. The average rutting depth of the dynamic repairs was $10.36 \mathrm{~mm}$ whereas for static repairs it was $14.82 \mathrm{~mm}$. High-level deformation was observed for the static repair constructed in slab $\mathrm{S} 14$, with a rutting depth of $18.66 \mathrm{~mm}$. In general, the rutting depth of the static repairs was not as consistent as that of the dynamic repairs. Furthermore, no stripping was observed in all the tested repairs and no significant rutting occurred for all the repairs tested at $4^{\circ} \mathrm{C}$ (Figure $9($ b)).
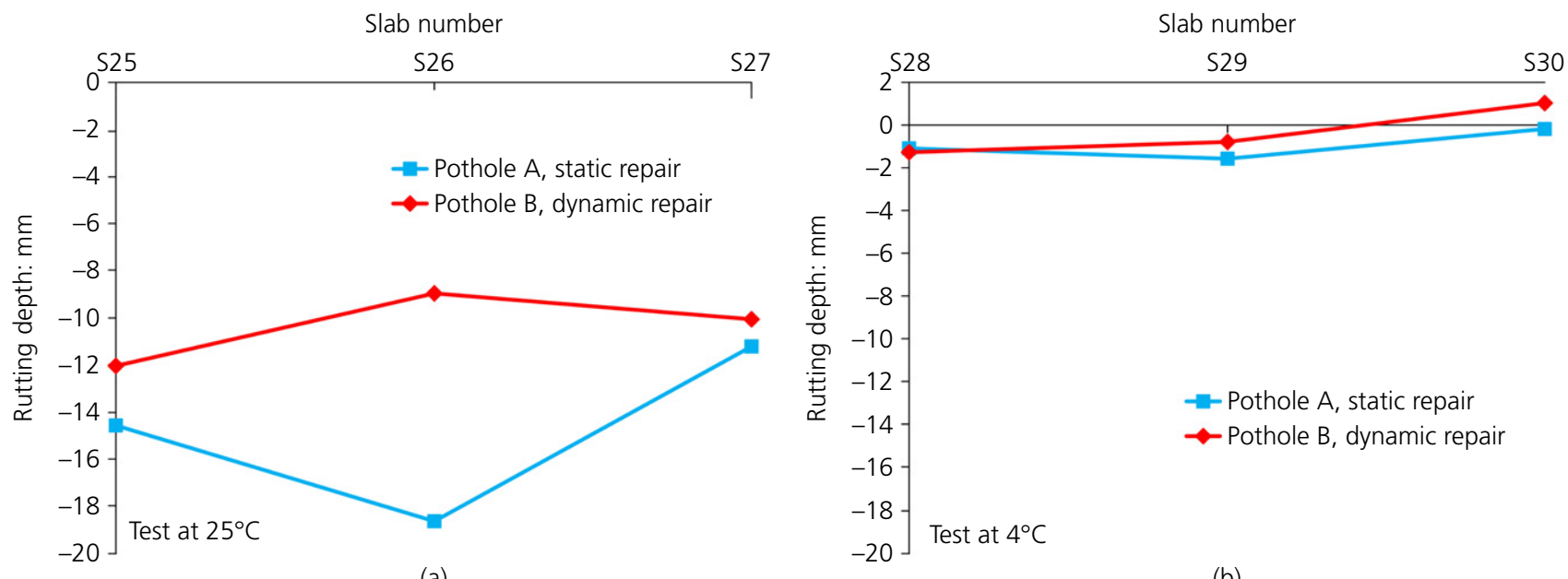

(a)

(b)

Figure 9. Rutting depth at (a) $25^{\circ} \mathrm{C}$ and (b) $4^{\circ} \mathrm{C}$ after 20000 cycles 

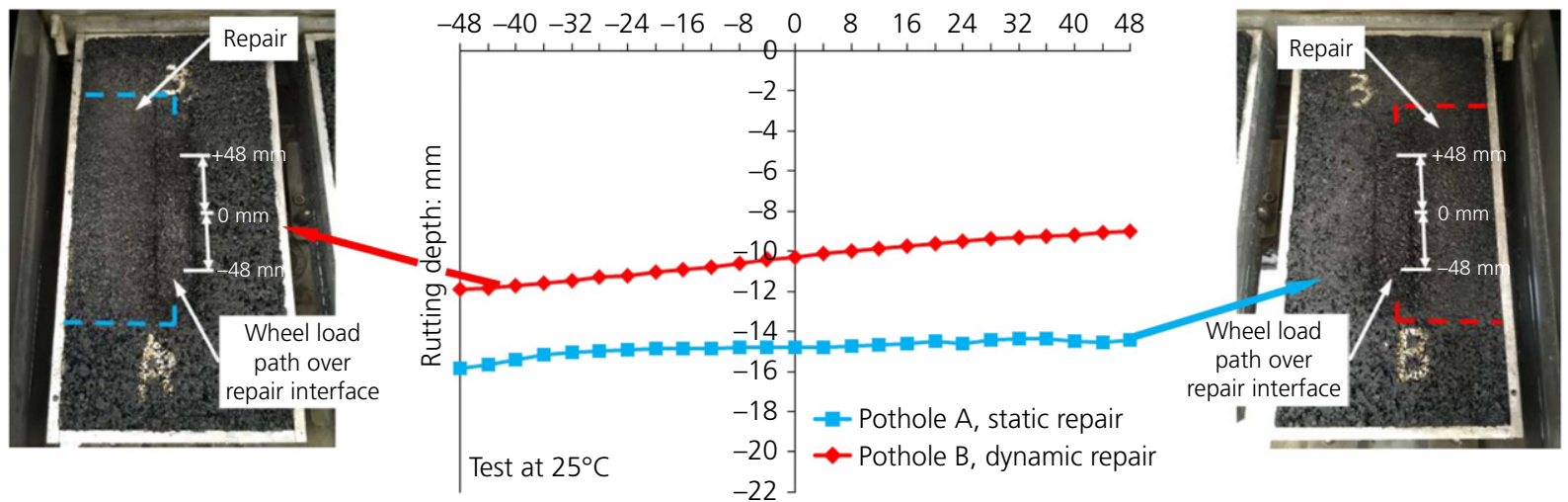

(a)

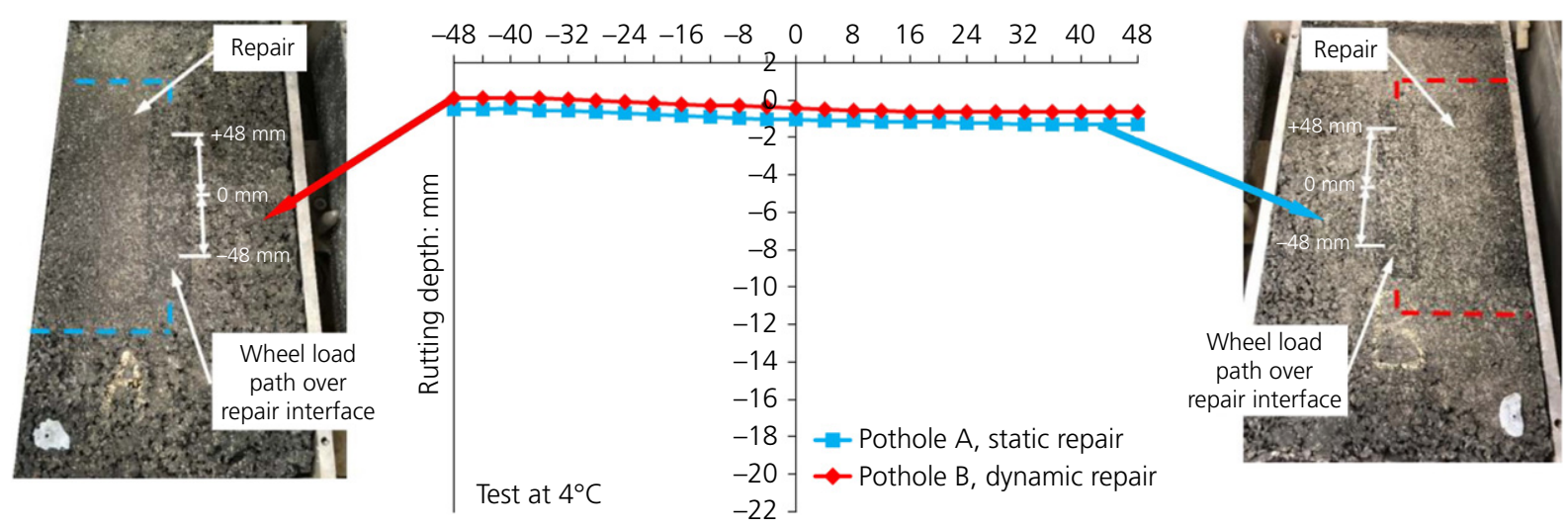

Distance from centreline: $\mathrm{mm}$

(b)

Figure 10. Longitudinal average rutting profile in the repair interface at (a) $25^{\circ} \mathrm{C}$ and (b) $4^{\circ} \mathrm{C}$ after $20000 \mathrm{cycles}$

\section{Conclusions}

The following conclusions are drawn from this research.

- Dynamically heating a pothole excavation increases pothole repair interface bonding. This is due to higher interlocking between the aggregates of the host pavement and the hot fill mixture.

- To achieve higher interface bonding for dynamic repairs, a heating time of approximately 10 min was found to be sufficient. This avoids overheating the asphalt and heating a larger area of mixture than expected or needed.

- The rutting resistance of the dynamic repairs at the repair interface was higher than that of the static repairs. However, more tests are recommended to determine the stripping point and evaluate the resistance to moisture damage of dynamically heated repairs.

- Preheating a pothole excavation with infrared heat prior to filling and compaction increases the durability of the repair.

\section{Acknowledgements}

This work was financially supported by International ChemCrete Corporation, Texas, USA, EPSRC, Brunel University,
Epicuro Ltd and DAC Consulting (UK) Ltd. Nynas UK AB and Conexpo (NI) Ltd also supported by providing materials. Laboratory work was supported by Brunel University technical staff Neil Macfadyen and undergraduate student Aaron Mann. The authors would like to express their appreciation to Cooper Technology in the UK for providing the wheel tracking machine specifically designed for the dimensions of the tests samples used in this study and the support of their engineering team.

\section{REFERENCES}

Aashto (American Association of State Highway and Transportation Officials) (2004) T 324: Standard method of test for Hamburg wheel-track testing of compacted hot mix asphalt (HMA). Aashto, Washington, DC, USA.

Aashto (2005) T 209-05: Standard method of test for theoretical maximum specific gravity and density of hot-mix asphalt paving mixtures. Aashto, Washington, DC, USA.

Aashto (2007) T 166: Standard method of test for bulk specific gravity of compacted asphalt mixtures using saturated surface-dry specimens. Aashto, Washington, DC, USA.

Adlinge SS and Gupta A (2013) Pavement deterioration and its causes. International Journal of Innovative Research and Development 2(4): $437-450$. 
BSI (2005) BS 594-1: Hot rolled asphalt for roads and other paved areas. Specification for constituent materials and asphalt mixtures BSI, London, UK.

BSI (2016a) EN 13108-1: Bituminous mixtures - Material specifications. BSI, London, UK

BSI (2016b) EN 12697-35: Bituminous mixtures - Test methods, Laboratory mixing. BSI, London, UK

Byzyka J, Rahman M and Chamberlain DA (2018a) An innovative asphalt patch repair pre-heating method using dynamic heating. Construction and Building Materials 188: 178-197.

Byzyka J, Rahman M and Chamberlain DA (2018b) An improved interface temperature distribution in shallow hot mix asphalt patch repair using dynamic heating. International Journal of Innovative Research and Development, https://doi.org/10.1080/10298436.2018. 1559315.

Byzyka J, Chamberlain DA and Rahman M (2019) Development of advanced temperature distribution model in hot-mix asphalt patch repair. Proceedings of the Institution of Civil Engineers Transport 172(4): 199-209, https://doi.org/ 10.1680/jtran.17.00022.

Chatti K, Salama H and El Mohtar C (2004) Effect of heavy trucks with large axle groups on asphalt pavement damage. Proceedings of the 8th International Symposium on Heavy Vehicle Weights and Dimensions, Muldersdrift, South Africa. See http://road-transporttechnology.org/conferenceproceedings/ishvwd-8/ (accessed 20/06/2018).

Clyne TR, Johnson EN and Worel BJ (2010) Use of Taconite Aggregates in Pavement Applications. Minnesota Department of Transportation, St Paul, MN, USA, Publication MN/RC-2010-24.

Dawson A (2008) Water in Road Structures: Movements, Drainage and Effects. Springer Science+Business Media, Dordrecht, the Netherlands.

Du J (2015) Evaluation of asphalt pavement layer bonding stress. Journal of Civil Engineering and Management 21(5): 571-577.

Freeman TJ and Epps JA (2012) HeatWurx Patching at Two Locations in San Antonio. Texas Transportation Institute, College Station, TX, USA, Publication FHWA/TX-12/5-9043-01-1.

Highways England, Transport Scotland, the Welsh Government and the Department for Regional Development (2008) Manual of Contract Documents for Highway Works. Volume 1, Specification for Highway Works, Series 900 Road Pavements - Bituminous Bound Materials. See http://www.standardsforhighways.co. uk/ha/standards/mchw/voll/pdfs/series_0900.pdf (accessed 06/08/2018).

Huang K, Xu T, Li G and Jiang R (2016) Heating effects of asphalt pavement during hot in-place recycling using DEM. Construction and Building Materials 115: 62-69.

Lavin P (2003) Asphalt Pavements: A Practical Guide to Design Production and Maintenance for Engineers and Architects. Taylor \& Francis, London, UK.

Leininger CW (2015) Optimization of the Infrared Asphalt Repair Process. Master's Thesis, University of Maryland, College Park, MD, USA. See https://search.proquest.com/openview/ $5 \mathrm{~d} 63 \mathrm{e} 8 \mathrm{ff} 20 \mathrm{aa} 8561 \mathrm{ec} 9 \mathrm{f} 4 \mathrm{e} 81 \mathrm{~b} 6 \mathrm{fc} 75 \mathrm{fe} / 1$ ?pq-origsite $=$ gscholar $\& \mathrm{cbl}=$ $18750 \&$ diss $=y$ (accessed 20/06/2018).

Lesueur D and Youtcheff J (2013) Asphalt. In Environmental Degradation of Advanced and Traditional Engineering Materials (Hihara LH, Adler RP and Latanision RM (eds)). CRC Press, Boca Raton, FL, USA, pp. 647-686.

McDaniel RS, Shah A and Olek J (2012) Longitudinal Joint Specifications and Performance. Indiana Department of Transportation and Purdue University, West Lafayette, IN, USA, Publication FHWA/IN/JTRP-2012/29.

McDaniel RS, Olek J, Behnood A, Magee B and Pollock R (2014) Pavement Patching Practices. National Cooperative Highway Research Program, Transportation Research Board, Washington, DC, USA, Project No. 20-05, Topic 44-04.
Mfinanga DA, Ochiai H and Yasufuku N (1996) Traffic loading and environmental effects on asphalt pavement rutting. Memoirs of the Faculty of Engineering, Kyushu University 56(3): 149-169.

Nazzal MD, Kim S and Abbas AR (2014) Evaluation of Winter Pothole Patching Methods. Ohio Department of Transportation, Columbus, OH, USA, Publication FHWA/OH-2014/2.

Obaidi H, Gomez-Meijide B and Garcia A (2017) A fast pothole repair method using asphalt tiles and induction heating. Construction and Building Materials 131: 592-599.

Prowell B and Franklin A (1996) Evaluation of cold mixes for winter pothole repair. Transportation Research Record 1529: 76-85.

Prowell BD, Zhang J and Brown ER (2005) Aggregate Properties and the Performance of Superpave-Designed Hot Mix Asphalt. Transportation Research Board, Washington, DC, USA, Project No. 9-35.

Raposeiras A, Castro-Fresno D, Vega-Zamanillo A and RodriguezHernandez J (2013) Test methods and influential factors for analysis of bonding between bituminous pavement layers. Construction and Building Materials 43: 372-381.

Roberts FL, Kandhal PS, Brown ER, Lee D and Kennedy TW (1991) Hot Mix Asphalt Materials, Mixture Design and Construction, 2nd edn. National Asphalt Pavement Association Research and Education Foundation, Lanham, MA, USA.

Uzarowski L, Henderson V, Henderson M and Kiesswetter B (2011) Innovative infrared crack repair method. Proceedings of 2011 Conference and Exhibition of the Transportation Association of Canada. Transportation Successes: Let's Build Them, Edmonton, Canada.

Walker D (1984) How vehicle loads affect pavement performance. Wisconsin Transportation Bulletin 2: 1-4.

Wilson TP and Romine AR (2001) Materials and Procedures for Repair of Potholes in Asphalt-Surfaced Pavements - Manual of Practice. US Department of Transportation, Washington, DC, USA, Report No. FHWA-RD-99-168. 